\title{
Corte Penal Internacional: Génesis y Alcance
}

Rosembert Ariza Santamaría

Artículo recibido: 27/04/2010 Aprobado: 07/06/2010

arosembert@gmail.com

\section{RESUMEN}

La importancia del Estatuto de Roma radica en el impacto que tiene en las legislaciones internas, en particular si altera la Administración de Justicia; por esta razón es necesario establecer los alcances del Estatuto de Roma y las implicaciones en los crímenes cometidos en Colombia.

\section{PALABRAS CLAVE}

Soberanía, complementariedad, competencia, derecho penal internacional, Estatuto de Roma.

\section{ABSTRACT}

The importance of the Rome Statute lies in the impact on domestic legislation, particularly if it alters the Administration of Justice, which is why it is necessary to establish the scope of the Rome Statute and the implications for the crimes committed in Colombia.

\section{KEYWORDS}

Sovereignty, complementarity, competition, international criminal law, Rome Statute

\section{INTRODUCCIÓN}

La Corte Penal Internacional (CPI) es un organismo nunca antes creado en la historia del derecho internacional, ya que es la primera vez que se establece un tribunal internacional permanente de esta índole, contrario a los casos de los tribunales de Núremberg, Tokio, Ruanda y la ex Yugoslavia, que se establecieron únicamente para juzgar el caso concreto de los respectivos países.

Sumado a ello, el establecimiento de la Corte Penal Internacional a través del Estatuto de Roma, se puede considerar un avance jurídico y ético de la humanidad, pues expresa de manera inequívoca la voluntad de la Comunidad Internacional de no permanecer indiferente frente a hechos atroces en contra de la dignidad humana.

Al ser un tema tan amplio, enfocaremos el presente análisis en el impacto que la competencia de la CPI tiene sobre nuestro ordenamiento jurídico, especialmente en lo que se refiere a la administración de justicia.

Para ello es necesario revisar la génesis de la Corte Penal Internacional, los casos que está abordando, el impacto y la opinión que se tiene sobre la incorporación de este tratado en nuestra legislación, elementos que implican que el presente trabajo se centre más en la parte teórica que en la cuestión práctica, revisando

${ }^{1}$ Abogado de la Universidad Santo Tomás. Doctor en Sociología Jurídica de la Universidad Externado de Colombia. Docente Investigador Universidad Nacional de Colombia y Universidad Santo Tomás 
las diferentes obras que existen en Colombia sobre el tema; y la sentencia de constitucionalidad, que surgió en razón del examen al que fue sometido el tratado, por la Corte Constitucional, en aras de intentar una comparación entre la opinión de los doctrinantes y la concepción que tiene la Corte sobre este particular.

No se pretende lograr lo propuesto por Kai Ambos respecto a este tema en su obra sobre la parte general del derecho penal internacional, pero si empezar una exploración en esta línea:

La relación entre el derecho penal internacional y los derechos nacionales puede ser objeto de investigaciones comparativas sobre la implementación en el derecho interno de los Estados del ECPI (Estatuto de la Corte Penal Internacional). Esto adquiere cada vez mayor importancia con el continuo aumento de las ratificaciones. En este sentido, en Alemania ha sido presentado y aprobado el Código Penal Internacional Alemán (VStGB) y también en otros países ya se han aprobado o están en proceso de elaboración leyes específicas de derecho penal internacional. De este modo, el derecho penal internacional desplegará un efecto de irradiación directo sobre los derechos nacionales y la praxis de derecho penal. Frente a esto, también la doctrina y ciencia del derecho penal debe reaccionar con pertinentes proyectos de investigación (de derecho comparado). (Ambos, 2005:503)

\section{LA CORTE PENAL INTERNACIONAL}

La Corte Penal Internacional tiene su sede en La Haya, Holanda, y está compuesta por 18 magistrados de países diferentes. El Tratado que le dió origen fue suscrito por 120 países el 17 julio de 1998 luego de decenios debates iniciados por diferentes juristas.

Esta institución internacional busca contribuir a poner fin a la cultura de la impunidad, ya que como se dijo anteriormente, es el primer tribunal judicial de carácter permanente que dará eficacia sancionatoria a las normas del derecho internacional humanitario. Tendrá una jurisdicción más amplia que el Tribunal de La Haya y podrá investigar en el territorio donde se cometió el delito, para lo cual no necesitará autorización del Estado correspondiente. Podrá investigar y juzgar a individuos (no a Estados) acusados de cometer violaciones graves del $\mathrm{DIH}$; los crímenes dejan entonces de estar sujetos al principio territorial del Derecho Penal. Los crímenes de conocimiento de la CPI son el genocidio, lesa humanidad y los crímenes de guerra (está pendiente de aprobarse el crimen de agresión).

La CPI no trata de establecer una legislación paralela, actúa solamente ante la ineficacia o la falta de voluntad del Estado competente para juzgar, por ello se afirma en principio que la soberanía de los Estados miembros no se ve afectada, en virtud del principio de complementariedad, pero la duda se presenta en quién y cómo se evalúa la falta de voluntad de los Estados o la ineficacia del ordenamiento jurídico.

No tendrá competencia retroactiva, ni juzgará los delitos de terrorismo o narcotráfico, ni podrá aplicar la pena de muerte. Nadie quedará exento de su responsabilidad criminal por cargo oficial, aún cuando éste pueda conllevar inmunidad según el Derecho Interno.

¿Cómo saber quién va a juzgar los crímenes de lesa humanidad que por ejemplo se cometan en Colombia?, teniendo en cuenta que solo la CPI entrará a juzgar por la ineficacia o la falta de voluntad del Estado competente para juzgarlo. Pero, surge igual otras preguntas, ¿en qué consiste dicha "falta de voluntad o ineficacia"? ¿podría considerarse falta de eficacia lo laxo del proyecto de justicia y paz para el proceso con las autodefensas?, teniendo en cuenta que para muchos, las penas que allí se proponen no son suficientes para resarcir el daño que han causado, entonces en este caso, ¿cómo se decidiría quién tiene la competencia? ¿Quién administra justicia?

Por otra parte con fundamento en nuestra Carta 
Política, ¿es correcto ceder competencia en la acción penal?, hay que tener en cuenta la importancia de estas normas en nuestra legislación, las cuales son de orden público y obligatorio cumplimiento, adicionalmente se considera que el juzgamiento de dichos actos es una máxima expresión de soberanía por parte del Estado; entonces si la Constitución consagra la soberanía como un principio importante dentro del ordenamiento, ya que con base en esta soberanía es que se le da un marco de legitimidad a sus actuaciones, ¿es conveniente y permitido que la ceda a un organismo supranacional?

El 17 de julio de 1998 la comunidad internacional dio un paso decisivo en la lucha contra las violaciones de los derechos humanos y el derecho internacional humanitario, cuando los 120 países que votaron a favor de una corte internacional permanente decidieron crear esta instancia para investigar y sancionar los delitos más graves y castigar los responsables de tales actos.

Pero antes de este logro, se dieron con anterioridad proyectos que buscaban crear una corte internacional permanente, diversas circunstancias dieron al traste con la creación de éste sumándole además, que no existía un derecho internacional unificado y que el existente tenía muchos vacíos.

\section{GÉNESIS DE LA CORTE INTERNACIONAL ${ }^{2}$}

\section{a) La propuesta de Gustave Moynier}

La propuesta inicial de creación de un tribunal penal internacional fue la realizada el 3 de enero de 1872 por Gustave Moynier, uno de los creadores, y durante mucho tiempo, presidente del Comité Internacional de la Cruz Roja.

Esta instancia judicial internacional se dedicaría a hacer aplicar directamente sobre los individuos las normas del derecho internacional humanitario que la Cruz Roja comenzaba a desarrollar, pero cabe aclarar que los supuestos de violación de la Convención de Ginebra de 1864 y sus artículos adicionales de 1868 nunca llegaron a entrar en vigor.

Una clara inspiración para Moynier fue el Tratado de Washington que firmaron Estados Unidos e Inglaterra, para someter ante un tribunal arbitral el asunto de las reclamaciones de Estados Unidos contra el Reino Unido por los daños que el corsario confederado Alabama le había causado a la flota estadounidense. De este tratado Moynier retoma el preámbulo del proyecto que contenía 10 artículos y de donde copia el modelo arbitral. La propuesta de Moynier solo tuvo aplicación de manera nacional en España cuando la Cruz Roja la retomó para aplicarlas a nivel interno.

\section{b) Las conferencias de paz de La Haya de 1899 y 1907}

El Derecho de la Haya está compuesto por un conjunto de convenios adoptados en las conferencias que tuvieron lugar en la Haya en 1899 y 1907, en las cuales se aprobaron temas referentes al arreglo pacífico de controversias, a las reglas y usos de la guerra terrestre y a la guerra marítima. Resulta interesante hacer un énfasis en el hecho de que se creara un tribunal permanente de arbitraje, aunque no era ni permanente ni tribunal en sentido estricto; pues marca una tendencia general hacia la creación de tribunales internacionales para la solución de conflictos. Además, con estas convenciones se lograron esbozar algunos puntos relacionados con la responsabilidad penal internacional.

c) El Pacto de Versalles: el intento de juzgar al Káiser Guillermo II.

Con el advenimiento de la primera guerra mundial se cometieron muchas atrocidades contra la población civil, generándose en la opinión pública, la idea de responsabilidad contra las tropas de los Estados vencidos y su juzgamiento por parte de los Estados vencedores.

\footnotetext{
${ }^{2}$ En este apartado sigo los textos de varios autores, entre ellos: Botero (1999), Camargo(2001) y lo publicado por la Comisión Andina de Juristas(2001)
} 
Es justamente con la conferencia de Versalles que se crea una comisión sobre la responsabilidad de los autores de la guerra y el cumplimiento de las penas, con el fin de castigar a todos los enemigos considerados culpables de incumplimientos de las leyes, usos de la guerra y de las leyes de humanidad.

En esta conferencia, la mayor parte de sus miembros querían crear un tribunal internacional para perseguir y enjuiciar a los altos mandos, incluido el Káiser Guillermo II de Hohenzollern, por las violaciones a los principios del Derecho de gentes tales como resultan de los usos establecidos entre naciones civilizadas, de las leyes de humanidad y de las exigencias de conciencia pública. Unos cuantos países tenían ciertas dudas respecto de la responsabilidad de los jefes de Estado, y por lo impreciso de la expresión "principios y leyes de la humanidad". (Urios, 2003:27)

Finalmente, después de una difícil negociación, se llegó a un compromiso entre las dos opiniones que se refleja en los artículos 227, 228, 229 .

En el artículo 227, se aseveraba que el Káiser Guillermo II de Hohenzollern era responsable "de un delito de suma gravedad contra la moral internacional y la inviolabilidad de los tratados". Así pues, para juzgar al emperador, las Potencias aliadas aprobaron la conformación de un "tribunal especial" compuesto por jueces elegidos por Estados Unidos, Gran Bretaña, Francia, Italia y Japón. "En su decisión, el tribunal deberá guiarse por los más altos designios de política internacional, con miras a reivindicar las obligaciones solemnes de los compromisos internacionales y la validéz de la moral internacional". (Urios, 2003:26-27)

Las disposiciones de este artículo anticipaban la creación de la categoría de "crímenes contra la paz", que surgiría después de la Segunda Guerra Mundial. A su vez los artículos 228 y 229 constituyeron el derecho de las potencias aliadas a enjuiciar y sancionar a los individuos responsables de "violaciones de las leyes y costumbres de la guerra".

Especialmente, en el artículo 228 se afirmaba que "el Gobierno alemán reconoce el derecho de las potencias aliadas y asociadas a someter a los tribunales militares a las personas acusadas de haber cometido actos en violación de las leyes y costumbres de la guerra". Por lo tanto, el gobierno alemán tenía la obligación de entregar a "todas las personas acusadas", a fin de ser juzgadas por un tribunal militar aliado. Se disponía que, en caso de que un sujeto fuese señalado como "culpable de actos criminales contra nacionales de más de una de las potencias aliadas y asociadas", podía establecerse un tribunal internacional.

Finalmente la puesta en práctica de estas disposiciones fue imposible, gracias a la negativa holandesa de extraditar al emperador alemán, sumándole el hecho de que el Estado alemán renunció a entregar a los criminales de guerra, por considerar el Tratado de Versalles un Diktat o una orden. Tras una trabajosa negociación se llegó a acordar con el Estado alemán que fueran juzgados solo un limitado número de criminales por la Corte Suprema del Reich.

\section{d) El período de entre guerras.}

Después del intento fallido de instaurar un tribunal internacional, le siguieron otros no menos frustrantes. El primer intento tuvo lugar en la recién creada Sociedad de Naciones que fuera después el antecedente inmediato de las Naciones Unidas.

En el año de 1920, el Comité Consultivo de Juristas presentó una resolución, nunca aprobada, para establecer un alto tribunal de justicia internacional la cual fue considerada como demasiado avanzada, ya que no había un derecho penal internacional reconocido por los Estados. Sus avances se reflejaron principalmente en el terreno académico.

En 1934 los asesinatos del rey Alejandro de Yugoslavia y el ministro francés de Asuntos Exteriores, provocaron que Francia presentara un 
proyecto de tratado internacional contra el terrorismo en donde en uno de sus puntos se proponía un tribunal de orden internacional. Se elaboraron en 1935, 1936 y en 1937 dos proyectos que no tuvieron ningún éxito.

Tres fueron los obstáculos para que no se diera inicio a estos proyectos:

1. La soberanía seguía siendo omnipresente, y si se permitía que un tribunal internacional juzgara a sus nacionales se estaría violando este principio. Además el Derecho Internacional solo regía las relaciones entre los Estados.

2. Se criticaba la ausencia de un Derecho Positivo en la materia para aplicarle a los potenciales acusados, y para lo que muchos de los contradictores argumentaban que primero debería hacerse la creación del derecho y después del tribunal.

3. Y por último, no existía una clara conciencia de la creación de un tribunal penal internacional para evitar la guerra.

\section{e) De Núremberg y Tokio}

No fue sino hasta después de la segunda guerra mundial que se creó una conciencia de la necesidad de emprender juicios sobre los delitos cometidos contra las leyes de guerra, considerando no solo la responsabilidad de los Estados sino las responsabilidades de los individuos. Dentro de las propuestas que salieron a escena durante la época se resaltan la de Hans Kelsen, quien proponía el castigo de los criminales internacionales a través de un tribunal penal internacional, la de la International Comission for Penal Reconstruction and Development, la de la Comisión de las Naciones Unidas para los Crímenes de Guerra, y la más detallada, la de la London International Assembly, bajo el auspicio de la Sociedad de Naciones. En esta última se propuso un tribunal con competencia en un número limitado de crímenes de guerra.

Con el Acuerdo de Londres, suscrito el 8 de agosto de 1945, en vista de los atroces crímenes cometidos por los nazis y por los japoneses, las potencias aliadas concertaron acuerdos entre sí y, posteriormente, instauraron los Tribunales Internacionales Militares de Núremberg y Tokio "encargados del juicio y castigo de criminales de guerra por delitos carentes de una ubicación geográfica particular, independientemente de que dichos individuos estén acusados de manera individual, en calidad de miembros de organizaciones o grupos, o en ambas calidades". Estas jurisdicciones especiales tuvieron también en cuenta las nuevas categorías de crímenes contra la humanidad y de crímenes contra la paz.

El artículo 6 del Estatuto del Tribunal Militar Internacional de Núremberg, estableció las bases jurídicas para el enjuiciamiento de individuos acusados de los siguientes actos:

- Crímenes contra la paz: Planear, preparar, iniciar o hacer una guerra de agresión, o una guerra que viole tratados, acuerdos o garantías internacionales, o participar en un plan común 0 conspiración para la perpetración de cualquiera de los actos [arriba] mencionados.

- Crímenes de guerra: Violaciones de las leyes y costumbres de la guerra. A continuación se da una lista de ellos, en la que se incluyen, inter alia, el asesinato, el maltrato o la deportación para trabajar en condiciones de esclavitud o con cualquier otro propósito, de la población civil, de territorios ocupados o que en ellos se encuentre; el asesinato o el maltrato de prisioneros de guerra o de personas que se hallen en el mar; la ejecución de rehenes, el saqueo de la propiedad pública o privada, la destrucción injustificable de ciudades, villas 0 aldeas, o la devastación no justificada por las necesidades militares.

- Crímenes contra la humanidad: El asesinato, el exterminio, la esclavitud, la deportación y otros actos inhumanos cometidos contra cualquier población civil, antes de la guerra o durante ella, 0 las persecuciones por motivos políticos, raciales 0 religiosos, cuando sean cometidos al perpetrar un delito sujeto a la jurisdicción del Tribunal o en relación con tal delito, e independientemente de 
que el acto implique o nó una violación del derecho interno del país donde se haya cometido.

Como la Carta del Tribunal Militar Internacional fue adoptada tras la comisión de los crímenes, fue duramente atacada por considerarse que era una criminalización ex post facto en incumplimiento del principio nullum crimen sine previa lege (Urios, 2003:34) Para rechazar estas argumentaciones, el tribunal se refirió a las Convenciones de la Haya específicamente sobre los crímenes de guerra, y al Pacto Briand-Kellogg para los crímenes contra la paz.

Las decisiones del Tribunal de Núremberg fueron la base para dejar clara la supremacía del Derecho internacional sobre el nacional, la posibilidad de la responsabilidad directa del individuo y la prohibición del ius ad bellum, del antiguo derecho de guerra. De igual manera este Tribunal sirvió de modelo para el de Tokio, aunque con algunas diferencias, porque el primero fue creado mediante orden ejecutiva y por medio del Tratado de Núremberg, y el segundo mediante la Carta del Tribunal fue creado por los americanos con un carácter mucho más amplio.

f) La obra de la Comisión de Derecho Internacional CDI

El 21 de noviembre de 1947, mediante resolución 177 (II), la Asamblea General de las Naciones Unidas hizo un doble encargo a la Comisión de Derecho Internacional. Por un lado, la formulación oficial de los principios de Derecho Internacional reconocidos por el Estatuto y las sentencias del Tribunal Militar Internacional de Núremberg, y por el otro, la preparación de un Proyecto de Código en materia de Crímenes contra la Paz y la Seguridad de la Humanidad.

Más tarde, en su resolución 260 B (III) de 9 de diciembre de 1948, conjuntamente con la aprobación de la Convención de Genocidio, la Asamblea General invitó a la Comisión, como cuerpo experto encargado de la codificación y desarrollo del Derecho Internacional, a examinar si era conveniente y posible crear un órgano jurisdiccional encargado de juzgar a las personas acusadas de genocidio 0 de otros delitos que fueren de competencia de ese órgano en virtud de convenciones internacionales.

La CDI en varias oportunidades presentó proyectos que fueron aplazados en el marco de la guerra fría, en el que era muy difícil progresar en materia de definiciones de agresiones, y de crímenes de guerra.

\section{g) Los tribunales Ad Hoc para Yugoslavia y Ruanda}

El 25 de mayo de 1993, con la instauración de los Tribunales para el enjuiciamiento de crímenes cometidos en Yugoslavia (TPIY) y en Ruanda (TPIR), respectivamente, se dio un paso significativo en el largo proceso para desarrollar normas sobre la responsabilidad penal individual en virtud del derecho internacional humanitario. Estos Tribunales implican un progreso capital hacia la institución de una especie de jurisdicción permanente. Asimismo, permitieron alcanzar una mayor claridad respecto de la esencia de lo que se está transformando, en una suerte de código penal internacional, en el sentido previsto por la Asamblea General de las Naciones Unidas en su Resolución $95(\mathrm{I})$.

La variedad de resoluciones del Consejo de Seguridad de las Naciones Unidas sobre el establecimiento de tribunales para enjuiciar a individuos responsables de actos cometidos en Yugoslavia y en Ruanda, contienen disposiciones relativas a los actos punibles, en virtud del derecho internacional humanitario. En particular, en los artículos 2, 3, 4 y 5 del Estatuto del Tribunal Internacional para Yugoslavia se detallan los diferentes crímenes que son competencia del Tribunal.

El artículo 2, sobre las infracciones graves de los Convenios de Ginebra de 1949, otorga al Tribunal la autoridad de enjuiciar a personas que "cometan u ordenen cometer" dichas infracciones graves. El artículo 3, extiende el alcance de la competencia al cubrir las violaciones de las leyes y usos de la guerra. El artículo 4, por su parte, reproduce los 
artículos 2 y 3 de la Convención sobre el Genocidio.

El componente más relevante del tribunal de Ruanda, es que, por primera vez, en la tipificación de los crímenes contra la humanidad no se requiere que éstos se cometan en conexión con un conflicto armado, internacional o interno.

\section{h) Etapa Final: El desarrollo del Estatuto de Roma}

Los comités especial y preparatorio sobre el establecimiento de la corte

Impulsada por los tribunales de Yugoslavia y Ruanda, la Asamblea General de Naciones Unidas decidió continuar con el trabajo tomando como referencia el proyecto de estatuto creado por la CDI en 1994. A través de una resolución, la Asamblea General creó el comité especial sobre el establecimiento de un tribunal penal internacional, que tuviera supremacía sobre las jurisdicciones nacionales, al estilo de los tribunales $\mathrm{Ad} \mathrm{Hoc}$ de Yugoslavia y Ruanda; así, si el fiscal quería abrir una investigación, los Estados no podían detenerlo aduciendo su jurisdicción nacional. Sin embargo, durante las discusiones surgió la idea de la complementariedad de la corte, 0 sea que la corte solo podía interferir si el Estado no quería o no podía. Además se hizo una fuerte insistencia en que los crímenes que fueran juzgados por la corte no solo fueran enumerados sino también definidos.

Finalmente, la Asamblea General estableció un comité preparatorio al que invitó a participar a los Estados, a Organizaciones No Gubernamentales y a organizaciones internacionales, para que elaboraran un proyecto de texto modificado sobre la base del elaborado por la CDI. El comité celebró entre 1996 y 1998 seis sesiones y entre las 2 que se dieron en 1996, presentó un informe que proponía toda una serie de modificaciones al proyecto de la $\mathrm{CDI}$, del que al final no quedó mucho. De ahí en adelante la comisión trabajó sobre sus propios frutos y el nuevo proyecto se conocería con el nombre de "proyecto Zutphen", que sería el proyecto fundamental sobre el cual trabajaría la comisión preparatoria que se llevó a cabo entre el 16 de marzo y el 3 de abril de 1998.
En esta sesión se aprobaron cuatro documentos vitales para la conferencia de Plenipotenciarios: el proyecto de estatuto sobre el establecimiento de una corte penal internacional, el proyecto de acta final de la Conferencia Diplomática de Plenipotenciarios de las Naciones Unidas sobre el establecimiento de una corte penal internacional, el proyecto de reglamento provisional de la Conferencia Diplomática de Plenipotenciarios de las Naciones Unidas sobre el establecimiento de una CPI y el proyecto de organización de los trabajos de la Conferencia Diplomática de Plenipotenciarios de las Naciones Unidas sobre el establecimiento de una CPI. En estas sesiones quedaron claras las cuestiones sobre la complementariedad, pero sobre la pena de muerte no y esto produciría problemas en las negociaciones finales.

La Conferencia Diplomática de Plenipotenciarios de las Naciones Unidas sobre el establecimiento de la Corte Penal internacional (CPI) tuvo como sede la ciudad de Roma y contó con un amplio grupo de Estados (160), observadores, 20 organizaciones internacionales y una coalición de ONG'S que se mantuvieron al tanto de las reuniones. El objeto era encontrar un consenso y un apoyo político para que la corte pudiera funcionar en un futuro de manera efectiva.

Se presentaron muchos inconvenientes respecto de los crímenes que juzgaría la corte, el papel del Consejo de Seguridad en su relación con la corte, la jurisdicción inherente a ésta, y la misma respecto de nacionales de Estados que no hagan parte del estatuto. Finalmente, por petición de Estados Unidos se recurrió al voto para la aprobación del proyecto y se aprobó con 120 votos a favor, 21 abstenciones, 7 votos en contra, empezando así un nuevo mecanismo internacional que persigue los delitos que van en contra de la armonía universal y evita su impunidad.

Retomando nuestra unidad de análisis recabaríamos sobre la siguiente pregunta ¿la firma del tratado de Roma limita la soberanía respecto de una de las características esenciales de la soberanía como lo es laAdministración de Justicia? 
El Concepto de soberanía ha sido el producto de una larga evolución histórica, surgiendo así varias teorías y autores que hablen sobre ella. Sin embargo, el contexto en el que se formó la noción hacen de ella algo artificial y precario, lo cual se está notando con la internacionalización de instituciones que pertenecían solo a los Estados.

Durante los periodos posteriores a la época feudal con base en las teorías de Locke y de otros teóricos, se defendió la teoría de la Soberanía Popular para derrocar los Estados monárquicos de la época moderna. Pero el concepto de soberanía no se fundamentaría solamente en la teoría de la Soberanía Nacional, sino que tendría desarrollo para desembocar en otra teoría, la Teoría de la Soberanía Popular.

El término se acuñó en la Constitución francesa de 1793, la cual estableció que "la soberanía reside en el pueblo". Jean Jacques Rousseau, en "El contrato social", imputa a cada miembro del Estado una porción igual de la que denomina la "autoridad soberana"; ésta es posiblemente, la primera referencia teórica sobre la soberanía popular.

De acuerdo a esta tesis, se puede definir la residencia legal y efectiva del poder de soberanía en un conjunto social que se ejerce en y por la universalidad de los ciudadanos. Así el sufragio universal se convierte en un derecho fundamental y la condición ciudadana es igual para todos los de la comunidad, con autonomía de cualquier otro miramiento, salvo las limitaciones de edad o juicio.

El concepto de soberanía, se puede definir como el poder 0 autoridad que tiene una persona o un grupo de personas con derecho a tomar decisiones y a solucionar conflictos en el seno de una jerarquía política; el hecho de tomar estas medidas envuelve autonomía de los poderes exteriores y autoridad máxima sobre los grupos internos. ¿Pero es concebible este concepto de soberanía en la época actual, donde la globalización hace más pequeñas las barreras que existían en los antiguos Estados Nación?
Es menester en estos tiempos replantear el antiguo concepto de soberanía ya que los nuevos acontecimientos, tales como la globalización, los tratados de libre comercio y las nuevas jurisdicciones supranacionales como la Corte Penal Internacional CPI han generado que éste se rompa.

Cassese y Mireille (2007:44) afirman que:

Para comprender el estatuto de la Corte Penal Internacional es preciso recordar que no fue una imposición del Consejo de Seguridad sino el resultado de negociaciones, que produjeron una tensión constante entre una lógica de justicia penal y una lógica de soberanía. La Conferencia de Roma tenía el deber de alcanzar cierto equilibrio. En efecto, una deferencia absoluta a la soberanía de los Estados habría desembocado en una Corte Penal Internacional impotente.

Lo cierto es que en las reuniones preparatorias de la Conferencia de Roma y a lo largo de la propia reunión, se asistió a una guerra de trincheras continua entre quienes promovían una aplicación de la justicia internacional y quienes querían multiplicar las disposiciones del estatuto con el único objetivo de proteger la soberanía de los Estados.

\section{LaCPI en Colombia}

Colombia suscribió el Estatuto durante el gobierno del presidente Andrés Pastrana en Marzo del año 2000 y lo ratificó el 13 de Noviembre de 2002, pero con una salvedad, haciendo uso de la autorización señalada en el artículo 124 del Estatuto, a manera de disposición transitoria, en la cual no se acepta la competencia de la CPI sobre los crímenes de guerra, cuando se denuncie la comisión de estos crímenes por sus nacionales o en su territorio, por un periodo de siete años, contados a partir de la entrada en vigor respecto del Estado que haga la declaración.

Esta salvedad se llevó a cabo por motivos que se pueden denominar de "interés general", ya que 
durante los debates del proyecto de acto legislativo que incorporó a la Constitución colombiana el Estatuto de Roma, ${ }^{3}$ fue uno de los temas de discusión centrales tanto en el Senado como en la Cámara. Cabe recordar que en esta época estaba en plena marcha el proceso de negociación con las FARC, y muchos se preguntaban, si la ratificación no causaría un efecto inhibitorio sobre los actores armados, por ello, en los debates el planteamiento mayoritario se expresaba en los siguientes términos: "En efecto, algunos plantean que si se ratifica el tratado de Roma, el actor armado preferiría continuar en la guerra que verse obligado a comparecer ante la CPI, puesto que, aún a pesar de la amnistía y el indulto, ésta mantendría su competencia. Lo anterior haría, en consecuencia, fracasar la negociación", ${ }^{4}$ como es bien sabido y como se refleja en el párrafo trascrito, el Estado le estaba apostando todo al proceso de paz, por ello y por los motivos anteriormente expuestos, se optó por ejercer esta reserva.

A pesar de la reserva hay que subrayar, que la ratificación del Estatuto se consideraba de vital importancia para la nación, pues al estar el país inmerso en un estado de violencia y guerra continua, era fundamental "garantizar que los crímenes de lesa humanidad, los crímenes de guerra, el genocidio y la agresión, considerados como una afrenta no sólo a los colombianos y colombianas sino al género humano, no queden en la impunidad." 5

Debe decirse, que la aprobación interna del Estatuto debió hacerse por medio de una reforma constitucional previa, que lo hiciera coherente con el régimen constitucional colombiano, ya que se presentaban algunas incompatibilidades entre la Constitución y el Estatuto; estas incompatibilidades se dan porque en algunos aspectos, la Constitución colombiana otorga mayores garantías que las normas internacionales (Bloque de constitucionalidad) pero no se trataba de reducir las garantías sino de incorporar el Estatuto y aprobarlo con una norma de rango constitucional en la cual se aceptaran las particularidades del mismo, como una situación especial o como una excepción constitucional.

En la Sentencia C-578 de 2002, la Corte Constitucional colombiana se ocupó de analizar la constitucionalidad del Estatuto de Roma de la Corte Penal Internacional, en ella se reiteró la obligación de armonizar la legislación interna con los estándares internacionales mínimos de protección en materia de derechos humanos y derecho internacional humanitario, para definir sanciones y procedimientos penales de graves crímenes como el genocidio. En palabras de esta Corporación:

Según lo que establece el Estatuto de Roma, la soberanía de los Estados es limitada de varias formas. En primer lugar, porque es la Corte Penal Internacional -y no cada Estado Partequien decide cuándo un Estado no está dispuesto o no ha sido capaz de ejercer su jurisdicción. En segundo lugar, porque el análisis de la existencia de una causal de incapacidad o de indisposición de un Estado, supone que la Corte examinará las condiciones bajo las cuales el Estado ha ejercido o ejerce su jurisdicción. En tercer lugar, porque el ejercicio de las competencias soberanas de los Estados para definir las sanciones y procedimientos penales de graves violaciones a los derechos humanos tales como el genocidio, los crímenes de lesa humanidad o los crímenes de guerra, deberá hacerse de tal forma que resulte compatible con el derecho internacional de los derechos humanos, el derecho internacional humanitario y con los fines de lucha contra la impunidad que resalta el Estatuto de Roma. En cuarto lugar, porque cuando la Corte Penal Internacional admite un asunto, la jurisdicción nacional pierde competencia sobre el mismo. Por lo anterior, es necesario examinar dichas limitaciones. (Resaltado fuera de texto).

La Corte Constitucional revisó igualmente el instrumento internacional que contiene las Reglas

\footnotetext{
${ }^{3}$ Acto legislativo 02 de 2001

${ }^{4}$ Proyecto de acto legislativo No 014 de 2001 Senado. Ponente Gustavo Guerra Lemoine. Gaceta del congreso No 432

${ }^{5}$ Proyecto de acto legislativo No 014 de 2001 Senado. Ponente Gustavo Guerra Lemoine. Gaceta del congreso No 158
} 
de Procedimiento y Prueba, como el relativo a los Elementos de los Crímenes de la Corte Penal Internacional y su ley aprobatoria, la Ley 1268 de 2008, (Sentencia C- 801/09) y concluyó que resultan ajustados a la Constitución, en cuanto constituyen elementos valiosos para garantizar el funcionamiento independiente de la Corte Penal Internacional. Al mismo tiempo, agrupa en su contenido y propósito, distintos postulados que constituyen principios fundantes y fines esenciales del Estado Social de Derecho, como la dignidad humana, la efectividad de los derechos humanos, la convivencia pacífica y la consecución de un orden justo (arts. $1^{\circ}$ y $2^{\circ}$ de la C.P.). Ala vez, respeta el mandato del artículo $9^{\circ}$ de la Constitución, en cuanto su aplicación está subordinada al ordenamiento jurídico, no sólo por el hecho de someterse al trámite complejo de incorporación interna -aprobación por el Congreso y control de constitucionalidad- sino también, porque sus contenidos no se proyectan ni inciden sobre las acciones y decisiones internas que le corresponda adoptar a las autoridades del país.

Por último, el instrumento internacional examinado, complementario del Estatuto de Roma, se inscribe dentro del marco del artículo 93 superior, el cual faculta al Estado para reconocer la jurisdicción de la Corte Penal Internacional, admitiendo la existencia de tratamientos diferentes en materias sustanciales frente a la Constitución, en cuanto se entiende que éstos producen efectos exclusivamente dentro del ámbito del citado Estatuto.

Es claro, que las relaciones entre lo nacional e internacional, son relaciones de complementariedad, teniendo en cuenta que lo nacional no sobrevive sin lo internacional, al igual que no existiría lo internacional si no existieran los Estados nacionales, en este caso se estaría hablando de una sociedad globalizada. No obstante, también es notoria la necesidad de ejercer un control social a nivel internacional, frente a lo cual esta jurisdicción debe sustentarse y elaborar un marco de garantías o mecanismos organizacionales que incluyan el debido respeto a los derechos humanos.
No puede ni debe convertirse esta jurisdicción en un modo de colonialismo o neo-imperialismo en manos de una potencia que vulnere los derechos de las naciones y los pueblos, por tanto la jurisdicción penal internacional debe convertirse en complemento a los ordenamientos nacionales.

\section{¿Administración de justicia complementaria?}

Según la noción de jurisdicción complementaria, la CPI poseerá competencia para investigar y enjuiciar un asunto siempre y cuando un Estado no reivindique su jurisdicción. Los Estados siguen poseyendo el papel principal, pero, si no se lo arrogan o consideran que es imposible hacerlo, no demuestran interés en el asunto o proceden de mala fe; la CPI se hará cargo de ello para garantizar que se haga justicia. Está previsto, en particular, para intervenir en asuntos en los que no hay posibilidad de que los criminales internacionales sean apropiadamente procesados por los tribunales nacionales. Se recalca que la Corte es un órgano que complementará las jurisdicciones nacionales existentes, así como los procedimientos para la contribución judicial internacional en asuntos penales, y no tiene por objeto suprimir la competencia de los tribunales nacionales ni afectar el derecho de los Estados al pedir la extradición.

El concepto de jurisdicción complementaria es nuevo, y se deriva de la importancia de la cooperación de todos los organismos internacionales a los Estados del mundo, a la vez de la división de responsabilidades y derechos. Como tal, no se sabe de qué manera puede evolucionar, ya que todo Estado tiene una distribución de acciones definidas, a partir de la cual muchas personas pueden pensar lo difícil que resulta que un órgano judicial no cumpla con sus obligaciones de juzgar a aquellos que cometieren delitos. Frente a ello, solo basta revisar los acontecimientos actuales, en los que se hace evidente que la falta de juzgamiento sí se puede dar, situación que ha originado una conciencia colectiva sobre la creación de una jurisdicción complementaria, por la incompetencia de las respectivas jurisdicciones nacionales. 
La aplicación de este principio en Colombia tiene unos alcances que se circunscriben a la Ley de Justicia y paz, sobre ello en su reciente trabajo Kai Ambos, asegura:

Las discusiones sobre complementariedad de la Corte Penal Internacional (CPI) en escenarios de transición que involucran a autores de graves crímenes internacionales (core crimes) parten, fundamentalmente, del análisis en torno a la realización de una dimensión especial del deber jurídico de persecución penal, especialmente de la concreción de investigaciones y juicios en la determinación de responsabilidad penal por los aludidos crímenes. Con ello, a la vez, se discute sobre la manera como un Estado asegura el fin esencial del deber de persecución, evitando que las apuestas por la paz se proyecten como un marco de impunidad. En procesos de transición, es manifiesta la tensión que producen dichas apuestas frente al desenvolvimiento tendencialmente racional de la jurisdicción penal, especialmente por la contracción de su efectiva capacidad para investigar y juzgar hechos violatorios de bienes jurídicos considerados esenciales por el Derecho Penal Internacional (DPI). Por lo mismo, las reflexiones sobre complementariedad en estos escenarios se orientan a confrontar los contenidos del procedimiento judicial, para determinar el nivel de independencia e imparcialidad de sus avances, y la capacidad de la jurisdicción penal para el desarrollo de procesos penales y sus respuestas frente a posibles manipulaciones políticas del sistema judicial que pudieran estimular la confección de escenarios de impunidad, especialmente de hechos tipificados en los artículos 6, 7 y 8 del Estatuto de la CPI. (Ambos, 2010)

Sin embargo, lo ocurrido con la extradición de los jefes paramilitares, como la aplicación y poca efectividad de la ley de justicia y paz, deja dudas sobre la falta de voluntad del Estado. La opinión de Kai Ambos sobre este aspecto es la siguiente:
Acerca de la situación en Colombia, un análisis sobre la falta de voluntad debe poner en contexto los criterios establecidos por el artículo 17 (2) ECPI. En cuanto al propósito de sustraer de la responsabilidad penal a los miembros de los grupos paramilitares, la esencia del punto radica en la evaluación de la pena alternativa. En el fondo, dicha pena no significa en sí misma una desproporción en relación con el derecho a la justicia ya que no extingue automáticamente la pena principal. Por otro lado, el criterio de demora injustificada puede analizarse desde un enfoque absoluto, teniendo en cuenta los lapsos del proceso mismo, y un enfoque relativo, comparando los tiempos del proceso con los de la justicia ordinaria. Ambos enfoques enfrentan el problema de no encontrar información fiable sobre la duración de los procesos. De hecho solamente existe como dato relevante que el caso más avanzado en JP ha tomado por lo menos tres años después de la desmovilización y aún no está terminado. Por lo tanto, la demora injustificada debe valorarse más desde el punto de vista de la técnica y estrategia de investigación de la Fiscalía, tomando en cuenta que se trata de asuntos muy complejos debido a las exigencias jurisprudenciales de sistematicidad y generalidad en la investigación de hechos cometidos por los grupos paramilitares (Ambos, 2010).

Esta posición del tratadista nos deja muchas dudas sobre el alcance en materia de justicia y verdad de la Ley de justicia y paz, pues lo amplio de su interpretación nos permite inferir que los procesos pueden durar demasiado tiempo, lo cual resulta siendo un asunto de incompetencia técnica. Así las cosas, lo que está en cuestión de fondo, es la capacidad del Estado colombiano para procesar y juzgar a los miembros de este grupo ilegal, de lo cual también da cuenta el profesor Kai Ambos al afirmar:

La incapacidad está determinada por tres situaciones: 1) colapso "total", (2) colapso "sustancial" o (3) el "carecer" de un sistema de 
justicia nacional. El colapso total puede definirse como "una ruptura completa de la administración de justicia, ya sea debido a que el Estado pierde el control sobre el territorio o debido a la decisión interna de borrar la administración nacional de justicia. El colapso sustancial puede ser compensado mediante el desplazamiento de recursos y procedimientos a otro lugar. En ese sentido, la no disponibilidad (carencia) se superpone con el requisito del colapso sustancial. Con una interpretación literal amplia se podrían revelar por lo menos tres aspectos del concepto no disponibilidad: la no existencia de algo, la no accesibilidad a alguna cosa y la inutilidad de un recurso, independientemente de su existencia y accesibilidad. Sin embargo, el mero funcionamiento ineficiente de un sistema judicial, sus deficiencias internas, no podrían considerarse dentro del concepto de no disponibilidad. En cuanto a la situación en Colombia, por todo el marco institucional y su infraestructura, es claro que no se puede hablar de un colapso total del sistema de justicia en el sentido del artículo 17 (3) ECPI. Además, dado el concreto funcionamiento de todo el sistema de justicia y paz, tampoco se puede hablar de colapso sustancial (Ambos, 2010: 194-197).

Finalmente, ante la gran cantidad de víctimas, hechos denunciados y casos tratados en los procesos de Justicia y Paz, el profesor Kai Ambos recomienda la importancia de empezar a diseñar una estrategia global de investigación. Actualmente, los procesos que se adelantan son de carácter fraccionado y aislado $y$, a pesar de los altos índices de hechos delictivos, no reflejan adecuadamente el fenómeno de la macrocriminalidad y sistematicidad.

Con todo esto, contrario sensu al profesor Kai Ambos es posible que se constituyan elementos que permitan la intervención de la Corte Penal Internacional, pues, no parece factible que con el modo de trabajo actual se puedan terminar los procesos ya iniciados y mucho menos los todavía pendientes dentro de un tiempo razonable.

\section{COLOMBIA ANTE LA CORTE PENAL INTERNACIONAL}

Colombia al mantener un conflicto armado interno de más de 50 años, ha intentado en varios gobiernos realizar negociaciones con los grupos subversivos y paramilitares para lograr la paz en nuestro país. El caso de la negociación durante el gobierno Uribe (Justicia y Paz), en opinión de muchos, lo que ha generando es un ambiente de injusticia e impunidad, pues lo que hasta ahora ha logrado esta ley es la evasión de los perpetradores de crímenes de guerra de los grupos armados frente a la verdad, la justicia y la reparación de las miles de víctimas de sus acciones.

Esta falta de aplicación de la justicia colombiana para con los grupos armados, originaría la posible competencia de la CPI en el juzgamiento de dichos sujetos. El Artículo 17 (2) (a) afirma que este tribunal tendrá plena competencia en los casos en los cuales las personas ya enjuiciadas en el ámbito interno y la decisión judicial haya sido adoptada con el propósito de sustraer a la persona de su responsabilidad por crímenes que sean competencia de la Corte Penal Internacional. Pero la competencia en el caso colombiano no sólo podría ser asumida por este numeral, lo sería también al ser remitido el caso por el Consejo de Seguridad de las Naciones Unidas, conforme a lo establecido en el artículo 13 literal b del Estatuto de Roma.

Por otro lado, es necesario recordar que el fiscal de la CPI Luis Moreno Ocampo dirigió una carta al gobierno nacional solicitando información sobre el conjunto de hechos puestos a conocimiento de esa oficina y los cuales son objeto de investigaciones preliminares para verificar las situaciones, las cuales "prima facie parecen demostrar una situación grave". Esta información llegó a la CPI por medio de un documento que fue enviado a la Federación Internacional de Derechos Humanos (FIDH), y dos de sus organizaciones afiliadas en Colombia, el Colectivo de Abogados José Alvear Restrepo y el Comité Permanente de Derechos Humanos en el año de 2005, en donde solicitaban 
investigar a los comandantes de las Autodefensas Unidas de Colombia (AUC).

Varios casos son conocidos actualmente por la CPI, veamos algunos elementos de los mismos: ${ }^{6}$

\begin{tabular}{|c|c|c|c|}
\hline PAÍS & SINDICADO & ETAPA & DELITOS \\
\hline CONGO & $\begin{array}{l}\text { Thomas Lubanga Dilo, Líder } \\
\text { rebelde de la Unión de Patriotas } \\
\text { Congoleses (UPC) y jefe de las } \\
\text { Fuerzas Patrióticas de la } \\
\text { Liberación del Congo (FPLC). }\end{array}$ & JUICIO & $\begin{array}{l}\text { CRÍMENES DE GUERRA } \\
\text { Artículo } 8,2 \text { Otras violaciones graves de las leyes } \\
\text { y usos aplicables en los conflictos armados } \\
\text { internacionales dentro del marco del derecho } \\
\text { internacional, b, XXVI Reclutar o alistar a niños } \\
\text { menores de } 15 \text { años en las fuerzas armadas } \\
\text { nacionales o utilizarlos para participar } \\
\text { activamente en las hostilidades..." }\end{array}$ \\
\hline UGANDA & $\begin{array}{ll}\text { - } & \text { Dominic Ongwen } \\
\text { (Comandante) } \\
\text { - Okot Odhiamba } \\
\text { (Comandante) } \\
\text { - } \\
\text { Raska Lukwiya } \\
\text { (Brigadier General) } \\
\text { - Vincent Otti } \\
\text { (Segundo al mando) } \\
\text { - Joseph Kony } \\
\text { (Comandante en Jefe) } \\
\text { Ejército de Resistencia } \\
\text { del Señor }\end{array}$ & INVESTIGACIÓN & $\begin{array}{l}\text { CRÍMENES DE GUERRA } \\
\text { Artículo Octavo Numeral Segundo Literales c } \\
\text { numeral I (Actos de violencia contra la vida y la } \\
\text { persona) y literal e numerales I (Dirigir ataques } \\
\text { intencionalmente contra la población civil como tal } \\
\text { o contra civiles que no participen directamente en } \\
\text { el conflicto), V (Saquear una ciudad o plaza,) VI } \\
\text { (Cometer actos de violación, esclavitud sexual, } \\
\text { prostitución y embarazo forzado, etc.) } \\
\text { CRímENES DE LESA HUMANIDAD } \\
\text { Artículo } 7^{\circ} \text { literales a (asesinato), c (Esclavitud), } \\
\text { g (violación, prostitución y embarazo forzado, etc.) } \\
\text { y K (otros actos inhumanos). }\end{array}$ \\
\hline $\begin{array}{l}\text { REPUBLICA } \\
\text { CENTROAFRICANA }\end{array}$ & EN INVESTIGACIÓN & INVESTIGACIÓN & EN INVESTIGACIÓN \\
\hline SUDÁN & $\begin{array}{l}\text { - Ali Kushayb } \\
\text { (Lider de la milicia local } \\
\text { Yanyauid) } \\
\text { - } \\
\text { Ahmed Haroun } \\
\text { (Ex ministro del Interior) }\end{array}$ & INVESTIGACIÓN & $\begin{array}{l}\text { CRíMENES DE GUERRA } \\
\text { Artículo Octavo Numeral Segundo Literales c } \\
\text { numerales I (Actos de violencia contra la vida y la } \\
\text { persona) y II (Persecución de un grupo o } \\
\text { colectividad con identidad propia fundada en } \\
\text { motivos políticos, raciales) y literal e numerales I } \\
\text { (Dirigir ataques intencionalmente contra la } \\
\text { población civil como tal o contra civiles que no } \\
\text { participen directamente en el conflicto), V } \\
\text { (Saquear una ciudad o plaza), VI (Cometer actos } \\
\text { de violación, esclavitud sexual, prostitución y } \\
\text { embarazo forzado, etc.) y XII (Destruir o confiscar } \\
\text { bienes del enemigo) } \\
\text { CRímENES DE LESA HUMANIDAD } \\
\text { Artículo } 7^{\circ} \text { literales } 1 \text { a (asesinato), d(Deportación } \\
\text { o traslado forzoso de población), e (Encarcelación } \\
\text { u otra privación grave de la libertad física), f } \\
\text { (Tortura), g (violación, prostitución y embarazo } \\
\text { forzado, etc.), h (Persecución de un grupo o } \\
\text { colectividad con identidad propia fundada en } \\
\text { motivos políticos, raciales, etc.) y K (otros actos } \\
\text { inhumanos). }\end{array}$ \\
\hline COLOMBIA & POSIBLE INVESTIGACIÓN & $\begin{array}{l}\text { POSIBLE } \\
\text { INVESTIGACIÓN }\end{array}$ & POSIBLE INVESTIGACIÓN \\
\hline
\end{tabular}

${ }^{6}$ Algunos críticos hablan de la africanización de la Corte, pues los casos hasta ahora asumidos por la misma son los referidos a este continente. 


\section{AMODO DE CIERRE}

A partir del análisis que se realizó en el presente trabajo es posible constatar que la creación de la $\mathrm{CPI}$ se constituye en un avance de la humanidad en la lucha contra la impunidad. Esto se evidencia en los casos que ha venido tramitando este organismo internacional, en los cuales se busca el esclarecimiento de la verdad y el castigo a los autores de dichos crímenes.

Para nadie es un secreto que en la actual coyuntura, hay un factor ajeno a los Estados que va estrechando aquellos famosos límites dentro de los cuales estos ejercían su control soberano. Ese factor, es lo que hoy en día llamamos globalización, que para el caso objeto de estudio se vislumbró en los años 40 con los famosos juicios de Núremberg y posteriores tribunales ad hoc, que buscaban la defensa de los derechos inherentes a la persona humana, que durante largos años se vulneraron.

Frente a la soberanía de los Estados es posible admitir que este Tribunal Internacional no es un simple observador, al contrario, es un organismo complementario que ayuda a los países a administrar justicia en aquellos casos en los cuales no puedan o no quieran los Estados partes, ya que son éstos los que en un primer momento tienen la obligación de juzgar aquellos delitos que sean competencia de la Corte.
Además debe tenerse presente, que este organismo internacional sólo interviene en aquellos casos que sean de su competencia, y que el Estatuto le permite hacer pactos con diferentes Estados para lograr una cooperación en investigación o de cumplimiento de condenas, lo cual confirma la complementariedad de este Tribunal Internacional.

Pese a que algunos países consideren que la creación de este máximo Tribunal es un límite a su jurisdicción en materia penal, razón por la cual no han querido suscribir o ratificar el tratado (como Estados Unidos), de lo visto se puede colegir que es necesario un organismo penal complementario ya que muchos países, siguen cometiendo crímenes atroces que no podrían ser juzgados de otra forma y que por supuesto quedarían en la impunidad.

En Colombia nos resta esperar el desenlace de la Ley de justicia y paz, la cual está dejando sin reparación a las víctimas de los crímenes cometidos por los grupos paramilitares, imponiendo penas en extremo laxas. Este proceder del Estado en total contravía de las disposiciones del Estatuto de Roma, dará lugar a la intervención de la Corte Penal Internacional por considerarse que la falta de castigo se debe a la falta de compromiso de Colombia en el juzgamiento e imposición de penas aeste tipo de delitos. 


\section{BIBLIOGRAFÍA}

AMBOS, Kai. (2005) La parte general del derecho penal Internacional. Editorial Temis. Konrand Adenauer. Bogotá.

(2010). Procedimiento de la ley de justicia y paz (Ley 975 de 2005) y Derecho Penal Internacional. Deutsche Gesellschaft für Technische Zusammenarbeit (GTZ) GmbH. Nomos Impresores. Primera edición.

BOTERO, Reinaldo (et.al) (1999) Derecho Penal Internacional, sobre la penalización de las infracciones al derecho internacional humanitario y la Corte Penal Internacional. Universidad Javeriana. Bogotá. Plaza y Janes.

CASSESE, Antonio, MIREILLE Marty (2007) Crímenes Internacionales y jurisdicciones Internacionales. Colección Vitral, Bogotá, Grupo editorial Norma.

Comisión Andina de Juristas. (2001) La corte penal internacional y los países andinos. Lima.

URIOS, Moliner Santiago. (2003) La Corte Penal Internacional (un estudio interdisciplinario). Ed. Tirant lo blanch, Valencia.

SANDOVAL, Jaime Alberto. (2001) Incorporación de la Corte Penal Internacional. Análisis Frente a la Legislación Colombiana

VILLANUEVA Javier y ABAD José. (2001) Jurisdicción Penal Internacional. Librería Jurídica Sánchez Ltda.

\section{JURISPRUDENCIA CONSULTADA}

Corte Constitucional

Sentencia C-578/02

Sentencia C-801/09

\section{NORMAS CONSULTADAS}

Estatuto de Roma

Proyecto de acto legislativo No 014 de 2001 Senado. Ponente Gustavo Guerra Lemoine. Gaceta judicial No. 158, 248y 432.

Proyecto de acto legislativo No 227 de 2001 Cámara. Ponente Carlos Germán Navas Talero

\section{Páginas de internet consultadas}

www.iccnow.org

www.derechos.net.

www.cinu.org.mx 